\title{
Rollout of Business Partner Networks from Selection to Implementation
}

\author{
Dr. Douglas K. PETERSON \\ (corresponding author) Academics-International, Inc \\ 1766 Avery Plaza, Fort Collins, COLORADO, USA \\ E-mail: dpeterson@academics-International.org
}

Dr. YuanYuan XING

Lioaning University

Shenyang, LIOANING, CHINA

E-mail: Xingyuanyuan@lnu.edu.ac

Received: April 6, $2020 \quad$ Accepted: Sep. 22, $2020 \quad$ Published: October 1, 2020

doi:10.5296/jmr.v12i4.17345 URL: https://doi.org/10.5296/jmr.v12i4.17345

\begin{abstract}
This paper covers a methodology for rolling out large initiatives in non-linear ways. Based on cooperation network formation theory, a cooperation network can be constructed from the multi-distance perspective under variables that better align business with the SDGs of the UN, the Paris Accord and the agendas of international organizations. It is apparent that business organizations play a central role in the addressing of the SDGs, however all that glitters isn't gold. There is poor transparency and rampant corruption in Asia, Africa, Eastern Europe, and Russia. With this in mind, a structure can be built that anyone can master with the use of an app. It would take a very large initiative to bring a structure to bear that transcended ad hoc assessment for superficiality and judgement. It would be highly possible to build assessment and transparency structures that allow a within and between company, cultural, and unilateral or multilateral view as well as a larger and more granular examination of industry, company reputation, strategy, finances, supply chain, delivery, and interactions with government and society. This paper proposes a simple mechanism using factor analysis and regression that can be built into the structure of app functionality. To use this, it is important to gather qualitative data, but more so to select quantitative data from which greatest opportunities can be derived and compared with qualitative data on culture and capacious capital structures. Data can be
\end{abstract}


demographic, corporate operations, cultural typology, human development, transparency, industrial or economic weakness.

Keywords: Sub-Saharan Africa, supplier due-diligence, cooperation network, virtual network, gravity modeling, variable distance modeling. 


\section{Introduction}

Large network integration methodology studies (Song, Sun, 2016) mainly focus on basic operations, practical obstacles, and implementation. This paper fills a gap because it describes a methodology for efficient construction and rollout of a very large initiative of cooperative networks, in this case, for due-diligence discovery for international organizational partner selection (Maturo, 2007). Based upon simple statistical input rather than typical and more inductive topics of policy, communication, connectivity, unimpeded activity, circulation, and complex human factors, this paper delivers an innovative approach to supplier assessment and cooperation (Barnard, Z, VanDer Merwe, 2016; Bollag, 2004).

This paper generally posits that attributes of these networks must be researched based upon cooperation mechanisms that create interconnection, inter-operational structures, diversified approaches promoting institutional discovery characteristics and cohesive interaction. This is rather unique. Some authors focus more on the nomology and fruitful results in network cooperation where generally players and their organizational, group, environmental and human structures can focus on cooperation, connectivity, and production. Others focus on the action plans for remediation if a partner organization looks attractive on other characteristics.

Fundamentally, this paper views interinstitutional partner analysis, mobility in and out of network, task orientation progression, international data sharing of best practices, and application of any level of economic, intellectual, or social and sustainable products of trade or process ( $\mathrm{Li}, \mathrm{Liu}, 2016)$. The contributions of this paper are the (1) establishment of a practical large initiative rollout mechanism that anyone with a simple knowledge of statistics can calculate and implement via app, (2) creation of a universal example or analysis and improvement, (3) support for statistical modeling, (4) discussion of policy and application, (5) discussions of applications for other projects like health and networks (Plotnikov, Verkakova, (2015) (6) economic integration, and (7) application examples for establishment of political cooperation unions and alliances.

The construction of our cooperation network is based on cooperation network formation theory where there are four main methods available to study cooperation network formation.

These are the case study, experimental research, game theory, and social network analysis. Based upon these concepts and methods, two interpretation paths of the cooperation network formation theory seem to shake out. They are predictors as benefit-based antecedents and opportunity-based consequences. Benefit-based antecedents place special emphasis on explaining the necessity of cooperation network formation through cost minimization or benefit maximization. For example, geographic proximity or shared technical and al logistics infrastructure for information and network information and exchange can reduce costs of addressing benefit-antecedents where benefit-based cooperation between resource complementary opportunity-based outcomes and project, agency, or partner welfare.

Opportunity based outcomes focus on the possibility of establishing cooperation network formation. For instance, network nodes and edges based upon similar socio-cultural backgrounds are more likely to achieve cooperation. In fact, the quality of the relationship 
between the cooperation participants determines the mobility of the resources, their communication and coordination, stable symbiosis over time, centrality of network benefits, and formation of institutional and intergovernmental cooperation. This assumes that governments, trade organizations, or regulatory bodies need to be consulted and enlisted in activities like these. In fact, it may be easier to forego governmental influence entirely because if favoritism or corruption. The question, however, is how much "motivation" is required for adequate government recusal.

\subsection{Smith, Hecksher, and Olin}

There is extensive literature on the impact of cooperation benefits and cooperation predicting international trade flows. In terms of absolute advantage, Smith (1903) proposes a factor endowment theory and emphasizes that factor endowments play a decisive role in, while Hecksher and Olin (H-O) propose a plentiful number of qualified businesses can go to institutions where there is a specialized cost-core. The $\mathrm{H}-\mathrm{O}$ model explains normatively how a country should operate and when resources pinpoint a preferred balance between two countries, or country, international organization, and contracting business (Kostova, 1997).

This model isn't limited to tradable commodities, but it also incorporates other production factors such as labor where the costs vary widely. By extension, countries with distinctive competencies for partner development and technological capabilities should benefit from that.

Finally, the Linder Hypotheses (1989), outlines and explains these theories. It states that countries with similar incomes require similarly valued products and that leads them to competition of distinctive capability or market segmentation according to competency.

In this study, $\mathrm{H}-\mathrm{O}$ is used to evaluate supplier capability and more specifically the equilibrium of potential partners within one project bid when the bidders have varying specialties and resources. It emphasizes the export of goods and services that require crosscultural factors of interaction that one potential partner or contractor has in abundance and can be brought to bear, but with potential uncertain fit. In context, organizational systems should emphasize the import and export of services and goods, however it isn't usually clear how cross cultural issues and industrial norms might affect an organization, and how it could be seen in proper due diligence. Many SMEs try to go it alone without adequate resources. However these programs are the ones that are expensive to envision, create, manage, fund, maintain, and discover (Lin, Plastovik, (2008); Tinbergen and Poyhonen (1962), however I do suggest in this paper that the processes can be automated and adapted to almost any use.

Inspired by the law of universal gravitation in physics, Tinbergen and Poyhonen (1962) establish the gravity model to study the factors influencing international flow and concluded that economic strength and geographic distance are the main factors operating tables flows. The gravity model successfully applied to the positive research of international flows in terms of cooperation opportunity factors (Lutz, Smetschka, Grimes, 2017). There is a wellestablished literature exploring the impact of cultural and institutional factors on flows, another point of interest. Another good stream of research that informs scholars and consultants who find that cultural differences have a significant impact on trade in services and goods flows, while still 
others believe the cultural distance increases the difficulty of market transactions and bilateral trade flow, cooperation, and sustainability. (Qi, Li, 2012). First, as a reduction in production costs, and second, increasing affinity parameters of contractors. More scholars still feel that institutional factors affect its international cooperation period with the concept of institutional distances (DeGroot, Linders, Subramanian, (2004). Proposed and defined here as the differences between organizations in terms of control, norms, and cognitive systems. New consensus has been reached to the variable selection and sample differences, although some find that organizations with similar systems are more active in multilateral or bilateral trade (Hecksher, 1919).

\subsection{Cultural Factors}

It is possible to lay a foundation and method basis for the research of cooperation network construction. As an example, in choosing vendors from Sub-Saharan African (SSA) suppliers there is a choice of suppliers from 48 countries, 48 national governments, countless small towns, tribes, languages, religions, and identifiable cultures. There are also many, many choices outside the SSA area. In terms of choosing contractors for higher education, in SSA there are roughly 466 colleges and universities, and 172 medical schools. In their choices of suppliers who the UN or other international organizations may support, the choices should align, but even then align in differences in indirect expenses (read corruption into this) and qualification of provider. Within the UN, and according to Jeff Sachs, the choices are difficult as there are no particularly standard decision frameworks that provide definitive outcomes. The choices become more and more difficult depending upon market players entering and leaving this perfectly competitive field. As is the case everywhere, there are also many organizations in support, but little information as to who they are, and what their real reputations might be. Diversified cultural and institutional members must consider the cooperation benefit factors, opportunity factors, sustainability factors. Therefore, the cultural principles of facilitation, friendliness, and complementarity of cooperation network formation theory as well as the geographic factor endowment, cultural, an institutional distances may be selected as variables to build our gravity model and expand our understanding of geographic, factor endowment, cultural, and institutional distance.

\subsection{Variables and Model Formatting}

Based upon cooperation benefits, the network formation theory expands the constructs so location and complementarity of cooperation can be considered. Cooperation and facilitation can reduce cooperation, opportunity, operational, contract adherence costs, and even performance bonds when those appear useful. All are beneficial to the parties in a potential transaction investigation, however, convenient exchanges and strong complementarity of factors can only provide basic antecedent conditions. Considering the friendly relationships among countries is also necessary in the cooperation network and formation must be based also on cooperation opportunities, and cooperation principles. From the two aspects of cooperation benefits and opportunities, metrics for geographic, factor endowment, cultural, and institutional in multiple distances are in fact able to measure multiple distances and measure the comprehensive distance indices. 


\subsection{Four Distance Variables}

There are many potential choices of variables that can help us explain, predict, and control the success of choices and order of implementation, and the analyst can use whatever $\mathrm{s} / \mathrm{he}$ desires.

The modeling is all the same. For us... there's geographic distance, or DIS. Generally, the greater the geographic distance between two countries, the higher the exchange risk and curriculum costs as well as communication costs. These may not be beneficial for the realization of cooperation between two countries. But according to the distance calculation method introduced by Soloanga (2001) the formula for relative geographic distances is as follows in Equation 1, just below.

$$
\text { (1) } D I S_{i j t}=\frac{G D P_{j t}}{G D P_{w t}} * D I S
$$

Where $\boldsymbol{D} \boldsymbol{I} \boldsymbol{S}_{\boldsymbol{i j t}}$ is the relative geographic distance between country i and its trading partner, country j in year t. $\boldsymbol{G D} \boldsymbol{P}_{\boldsymbol{j} t}$ denotes the gross domestic product of country $\mathrm{j}$ in year t. $\boldsymbol{G D} \boldsymbol{P}_{\boldsymbol{w} t}$ if world GDP in year $t$, and DIS the absolute distance between the capital of country I and the capital of exchange partner in country j. GDP and DIS data are obtained from the World Bank (WB) Group databases and from the Research in Expertise in World Economy (CEPII) database. Geographic distances is understood as relative geographic distance.

Second, factor endowment distance (DKL) is expressed (c.p.) as complementarity between two countries where the greater the co-demand for products builds necessity for interaction cooperation. This is the absolute value of two States capital to labor log in which capital is based in constant price. Figures were obtained by Penn World. Missing values are interpolated through a forecasting function.

Third, the variable regarding cultural distance (CD) is the distance between export country and its ed exchange partner due to differences in ideology, delivery, curriculum, politics, preparedness. Generally, these are along the measured difference in Hofstede's dimensions. The calculation formula is as shown in Formula 2, just below:

$$
\text { 2) } C D_{j}=\Sigma_{n} i=1\left[\left(C_{i j}-C_{i h}\right)^{2}\right]+\frac{1}{R_{j t}} /
$$

As $\mathrm{j}$ is the trading partner country. $\mathrm{CD}_{\mathrm{j}}$ is the cultural distance in organizational and economic systems and institutions $\mathrm{j}$, where $\boldsymbol{C}_{\boldsymbol{i} \boldsymbol{j}}$ is an index of cultural dimensions $\mathrm{i}$, of a trading ed system, and $\boldsymbol{C}_{\boldsymbol{i} \boldsymbol{h}}$ is an index in cultural dimension in country $\mathrm{C}_{\mathrm{x}} \cdot \boldsymbol{C} \boldsymbol{V}_{\boldsymbol{i}}$ is a variance of an index of dimensions $i$. also, $n$ is the number of cultural dimensions, and $R_{j t}$ the approximate since al cooperation between two countries. Missing data are filled in interpolation from neighboring countries.

Fourth, the measure of institutional distance (ID) represents the political and ideological distances and political-cultural distrust between countries and economic systems that serves to limit the degree of cooperation. Governance indicators from WB were used to enter the 


\section{Macrothink}

Journal of Management Research

ISSN 1941-899X

2020, Vol. 12, No. 4

dimensions of accountability and voice, political stability, absence of violence, rule of law, and corruption control. The distance method was done according to the calculation method of $\mathrm{Li}$ and Liu (2016) and quantified according to the WB Worldwide Governance Indicators. Equation 3 is just below.

$$
\text { 3) } I D_{t}=\frac{\frac{\Sigma_{j}\left[1_{i j} 1_{c j}\right]}{\max I_{i j}-m i n I_{i j}}}{\operatorname{man}_{i}}
$$

Where ID is the institutional distance between member a and ed exchange partner $b$.

Subscripts I, c, j, represent participating countries.

\section{Expanding the Gravity Model}

A main tool in this study is a gravity model. The traditional gravity model is used for analyzing the influence factors of bilateral and trade flow (Yin, Liu, 2007). In this study, I expand the model to estimate the parameters of four distance variables to which are geographical cultural distance institutional distance and differences in relative factor endowments. These parameters are used to improve the subjective weighting method and create complementary distance indexes to evaluate the exchange cooperation potential (Zhang, Peng, 2012). Based on the result this cooperation model was constructed.

\subsection{Modeling}

To determine the impact of geographic distance, factor endowment distance, cultural distance, and institutional distance on flow, this study uses the gravity model to complete positive research period the gravity model was first proposed by Tinbergen (1962), and when successfully applied to the positive research of international trade and flow. Based on the assumptions of constant elasticity of substitution, a null monopolistic competition in a single sector economy, Anderson (2000) theoretically introduced the multiple resistance model, laying a theoretical foundation for the gravity model. On this basis the gravity model is as follows in equation 4 :

$$
\text { 4) } \boldsymbol{X}_{i j}=\left(\boldsymbol{Y}_{i} \boldsymbol{Y}_{j} \boldsymbol{t}_{i j}\right) /\left(\boldsymbol{P i} \boldsymbol{P}_{j} \boldsymbol{Y}_{w}\right)
$$

The above formula shows that country $i$ exports to country $j$ are independent on the exchange scale of two countries $\mathrm{P}_{\mathrm{i}} \mathrm{P}_{\mathrm{j}}$ with bilateral resistance explained as $\mathrm{T}_{\mathrm{ij}}$, where and world nominal income $Y_{w}$ are entered and $D_{i}$ is the $m$ quantitative factor hindering the exchange between countries and $\mathrm{V}_{\mathrm{ij}}$ is $\mathrm{n}$ qualitative factors hindering exchange between factors including natural and human barriers. Based on this, these barriers are further divided into geographic distance (DIS), factor endowment distance (DKL), cultural distance (CD), and institutional distance (ID) in equation 5. After substituting equation 5 into equation 4 and performing a log-linear transformation, the formula is changed into: 
5) $l_{n} X_{i j}=-l_{n} Y_{w}+\left[l_{n Y i}+(\alpha-1) l_{n P j}\right]+\gamma m(1-\alpha) l_{n} D I S_{i j}+\gamma m(1-\alpha) l_{n} D K L_{i j}$

$+\gamma m(1-\alpha) \operatorname{lm} C D_{i j}+\gamma m(1-\alpha) l_{n} I D_{i j}$

Since composite price indices are usually not available, the above formula cannot be directly computed. Therefore, using the viewpoints expressed by Soloaga (2001), Isubstituted it with the relative geographic distance between the two countries. The country with the farther geographic distance had a lower output and generally a higher composite price index. After the above treatment I derivedthe following equation:

6) $\operatorname{lnXijt}=\beta 0+\beta 1 \ln Y i t+\beta 2 \ln Y j t+\beta 3 i n D I S i j t+\beta 4 \ln D K L i j t+\beta 5 \ln C D i j t$

\section{$+\beta 6 \operatorname{lnIDijt}+\boldsymbol{\mu i j t}$}

All countries are in the exporting regions, some more than others, so when each subject country is considered independently in its own time trend, the following final regression is obtained inserting a target country.

7) $\ln X_{i j t}=\beta_{0}+\beta_{2} \ln Y_{j t}+\beta_{3} \ln D I S_{i j t}+\beta_{4} \ln D K L+\beta_{5} i n C D_{i j t}+\beta_{-} 6 \operatorname{lnI} D_{i j t}+\mu_{i j t}$

Due to the serious lack of services in data, the data were obtained from the UNICOM database. $\boldsymbol{Y}_{\boldsymbol{j} t}$ denotes the economic scale of the belt and road country in year T. GDP was used to represent the economic scale of the country. The data were obtained from the World Bank. DIS - DKL space CD space IDIJT represent the geographic distance, factor endowment distance, cultural distance, and institutional distance between exporting nations.

\section{Scope of Study}

Organisme de Coopération Zones CASSE' is at present, nonexistent. Its basic scope however encompasses 48 countries, and include all regions of the African continent except for Saharan Africa. Complete data is not available in many nations, most notably the Democratic

Republic of the Congo, The Central African Republic, Mali, Malawi, Zimbabwe, and Mozambique. I worked with what I could get. The countries included in this study are in Table 2. 
Table 2.

\begin{tabular}{|c|c|}
\hline Region & Country \\
\hline West African Zone & $\begin{array}{l}\text { Senegal, Gambia, Guina - Bissau, Sierra } \\
\text { Leone, Liberia, Cote D’Ivoire, Ghana, } \\
\text { Benin, Togo, Nigeria. }\end{array}$ \\
\hline $\begin{array}{l}\text { Transition Zone - Between } \\
\text { Sahara and SSA. Generally } \\
\text { Islamic Countries. }\end{array}$ & $\begin{array}{l}\text { Senegal*, Gambia*, Guinea-Bissau*, } \\
\text { Burkina Faso*, Nigeria*, Chad*, Sudan*, } \\
\text { Niger*. }\end{array}$ \\
\hline Central African Zone & $\begin{array}{l}\text { Equatorial Guinea, Republic of Congo, } \\
\text { Nigeria, Central African Republic, Chad*, } \\
\text { Sudan*. }\end{array}$ \\
\hline East African Zone & $\begin{array}{l}\text { Rwanda, Burundi, Uganda, Kenya, } \\
\text { Ethiopia, Tanzania. }\end{array}$ \\
\hline Southern African Zone & $\begin{array}{l}\text { Angola, Zambia, Zimbabwe, Botswana, S. } \\
\text { Africa, Lesotho, Swaziland. }\end{array}$ \\
\hline
\end{tabular}

\begin{tabular}{|l|l|l|l|l|l|}
\hline Variable & Sample & Mean & StDev & Max & Min \\
\hline InX & 336 & 21.354 & 1.961 & 24.913 & 14.277 \\
\hline InYj & 336 & 24.797 & 1.646 & 28.448 & 20.141 \\
\hline InDIS & 336 & 1.495 & 1.690 & 5.123 & -2.887 \\
\hline InDKL & 336 & -2.063 & 1.073 & -0.209 & -7.556 \\
\hline InCD & 336 & 0.546 & .6486 & 1.842 & -.856 \\
\hline InID & 336 & -1.627 & .446 & -.5383 & -2.716 \\
\hline
\end{tabular}

Le OCZC Zone,

The Cooperation Africain Sin l'éducation Zone, or OCZC is proposed as an open AI cooperation network. At present, there are no proposals on the table, however the paper may serve as an impetus for exploration. In its proposed state it could incorporate as many as possible countries in SSA, but that would be unlikely because of the ideological, political, health, and al distances in these areas. In the above country membership table the countries $* * * *$ are not included because of data paucity or believability. 


\section{Results and Discussion}

Before regression, the variance inflation factor, or VIF, of each variable was tested. The VIF of each variable was less than 10 , indicating no serious multicollinearity in the model. To avoid the possible spurious regression problem in the model, the Levin-Lin-Chu test (2005), applicable to the same roots, and the Fisher ADF (2011) test, applicable to different roots, were both used to test the unit root of the data. The results showed that the level value, the first differencing value, and the second differencing value of each of the main variables in the model past the unit root test, so the T statistic and F statistic of the estimates of the model were valid. To choose the proper estimation technique, I performed the F test and Hausman test (2005). The results showed that panel techniques with mixed effects were more applicable to the regression than panel techniques with fixed effects or random effects, so I adopted panel effects with mixed effects. To reduce the impact of heteroscedasticity on the model, the cross-section weighted panel techniques with mixed effects was used for estimation. Results are shown in Table 3.

First, the control variable $\mathrm{Y}_{\mathrm{j}}$, the economic scale of cooperation is significantly positive at the $1 \%$ level in all regression results, supporting the basic conclusion of the gravity model that the flows between economies are directionally proportional to economic al scales.

Second, geographic distance (DIS) is significantly negative at the $1 \%$ level in all regression results, meaning the farther the geographic distance between two economies, the smaller the exchange and interdependence confirming the basic conclusion of the gravity model,

Third, the factor endowment distance (DKL) was negative and passed the $1 \%$ significance test, indicating that the smaller the factor endowment distance between two economies, the greater the exchange flows. This conclusion contradicts comparative advantage theory. Zhou (2017), in studying exchange flows, attributed a similar result to large initiatives in developing countries and emerging economies with relatively small factor endowment distance in the future where more data tests will be needed to determine the direction to the relationship.

Third, factor endowment distance, DKL, was negative and passed the $1 \%$ significance test, indicating that the smaller the DKL between two economies, the greater the tertiary al trade flows. This conclusion contradicts the competitive advantage theory, however Zhao (2017) attributed a similar result to the rollout of Belt and Road through the mid-East, Africa, and Europe. The process identified through developing countries and emerging economies with low factor endowment distances was one of rollout through developed to developing economies coming last. In these cases, DKL was only an estimation of the factor endowment distances.

Fourth, cultural distance (CD) was negative and significant at the $1 \%$ level, in line with the theoretical expectation that cultural distance has a negative effect on flows.

Fifth, institutional distances (ID) was positive and significant at the $1 \%$ level, indicating that the greater the institutional distance between two economies, the greater the flows of exchange. The conclusion is counter to the findings of Wan (2014), but is consistent with the conclusion of Li and Liu (2016). This is mainly due to the asymmetric effect of the institutional distance on 
flows. On the one consideration, for a trading partner with institutional risk, when the institutional distance between the two countries is small, the institutional distance between the two countries are similar and the experience gained by the two parties can effectively reduce their costs. On consideration, for one partner without institutional risk, a greater institutional distance means that the institution is this country is more developed and the institutional environment is better.

In the fourth model, the GDP of a target country, geographical distance, factor endowment, and cultural / institutional distance elasticity were $2.124,1.10, .072, .257$, and .324. If the GDP of the trading country or institutional distance increased by $1 \%$, economic flows would increase by $2.234 \%$ and $.324 \%$. If the GDP of the trading target country increased by $1 \%$, flows would increase by $1.094 \%, .702 \%, .257 \%$, and $.324 \%$. Finally, if the geographic, factor endowment, or cultural distance increased by $1 \%$, flow would decrease by $1.096 \%, .0720 \%$, and $.257 \%$. Geographical distance is the main factor affecting flow of the four distance variables, followed by institutional distance, cultural distance, and factor endowment distance.

Tabe 3. Estimates of panel techniques with mixed effects.

\begin{tabular}{|c|c|c|c|c|}
\hline Variable & Model 1 & Model 2 & Model 3 & Model 4 \\
\hline $\ln Y j$ & $\begin{array}{l}20.15^{* * *} \\
(.0287)\end{array}$ & $\begin{array}{l}2.118 * * * \\
(.0326)\end{array}$ & $\begin{array}{l}20.103 * * * \\
(.0462)\end{array}$ & $\begin{array}{l}2.124 * * * \\
(.049)\end{array}$ \\
\hline $\operatorname{lnDIS}$ & $-1.153 * * *$ & $-1.118 * * *$ & $-.075 * * *$ & $-1.096 * * *$ \\
\hline $\operatorname{lnDKL}$ & & $\begin{array}{l}-.049 * * * \\
(.0113)\end{array}$ & $\begin{array}{l}-.075 * * * \\
(.0118)\end{array}$ & $\begin{array}{l}-.072 * * * \\
(.0138)\end{array}$ \\
\hline $\operatorname{lnCD}$ & & & $\begin{array}{l}-.131 * * * \\
(0.284)\end{array}$ & $\begin{array}{l}-.256 * * * \\
(0.0304)\end{array}$ \\
\hline $\operatorname{lnLD}$ & & & & $\begin{array}{l}.0324 * * * \\
(.9607)\end{array}$ \\
\hline Adj-R ${ }^{2}$ & .0963 & .9614 & .9564 & .9607 \\
\hline $\mathrm{F}$ & $8000.130 * * *$ & $5134.710 * * *$ & $3366.641 * * *$ & $3028.081 * * *$ \\
\hline Sample & 360 & 360 & 360 & 360 \\
\hline
\end{tabular}

$* * *=\mathrm{p}<.01$. Parentheses are standard errors

Sixth, In summary, the regression results verified that flows between two economies are greater when the geographic distance, the factor endowment distance, and the cultural distance are smaller and the institutional distance is greater the regression results were still robust when using the uncertainty avoidance and government effectiveness indices as a proxy variable for cultural distance and institutional distance. I ran robustness tests using the Poisson maximum likelihood. The results of these were encouraging.

The results of the positive research of the expanded gravity model showed that geographic, factor endowment, and cultural and institutional distance have significant impacts on flow, 
proving the correctness of construction a cooperation network from a multiple distance perspective. Based on the results of positive verification, I assign weights to geographic factor endowment and cultural and institutional distance. It improved the comprehensive index method to evaluate the comprehensive distance indices between SA countries. The countries were further divided into different cooperation circles to lay the foundation for the design and construction.

The traditional methods used to determine the weights of indicators can be roughly divided into two categories: subjective weighting amounts, such as an analytical hierarchy process or a AHP as an expert evaluation model and comprehensive index model; And objective weighting methods such as advantage analysis, principle component analysis, and factor analysis. The subjective weighting method is based on the rich experience of experts to determine the importance of properties but is susceptible to human impact. The objective weighting method may result in the predetermined weights being inconsistent with the actual importance of the properties, although the weights may have a strong mathematical basis. Therefore, the comprehensive index method was modified based on the results of positive verification of a gravity model to compute the comprehensive distance indices between SSA and the shortcomings of both subjective and objective weighting methods.

There are SSA countries as samples an selected geographic, factor endowment, cultural distance, and institutional distance as four variables, so the sample matrix was XIJ, 48 * four.

I changed the mentioned data and a positive and dimensionless data. Based on positive research results, I change three variables: geographic distance, factor endowment, cultural distance, and positive data using reverse conversion methods. To preserve the variation information of the indicators, I adopted the averaging method to change the data into dimensionless data, matrix XI J $48 * 4$.

According to the positive verification results of the gravity model, beta $\mathrm{J}$, the coefficients of the geographic distance, factor endowment, cultural distance, and institutional distance were $1.096,072,256$, and 324, respectively. Using equation nine I obtained $F_{j}$, or the weights of the geographic distance, factor endowment distance, cultural distance, and institutional distance as $.618,7.03,8.15$, and .1942 respectively.

$$
\boldsymbol{f}_{j}=\frac{\boldsymbol{\beta}_{j}}{\Sigma \boldsymbol{\beta}_{j} j}=1,2,3,4, n
$$

In computation and ranking of comprehensive distance indices, I used equation tent to calculate the weighted mean of the geographic distance, the factor endowment distance, the cultural distance, and the institutional distance. I use the reverse conversion method to obtain the ranking of the comprehensive distance indices between SSA countries: 


$$
y_{i}=\frac{\Sigma X i j 0 f j i}{\Sigma f j i}=1,2,3, n
$$

the comprehensive distance indices are not absolute distance in space the distances only have relative meaning, so are only valuable when compared, so that the value could be negative or positive . The country with potentially negative smaller comprehensive distance indices would have the greater potential for deep cooperation, whereas a country with larger comprehensive distance indices from an SSA country would have a smaller potential for deep cooperation. In addition, the results in table 4 suggest that country here comprehensively closer to country here in SA are better matches than others according to World Bank data common Tanzania is higher than Senegal in institutional quality from 2007 to 2016. Generally, countries with a good economic environment area can reduce the uncertain factors on , reduce risks, and promote the development of cooperation.

Table 4. Comprehensive Distance Indices the CASSE Zone Against Fictitious Wealthy Country called "Nguvu".

\begin{tabular}{|l|l|l|l|l|l|}
\hline South Africa & Ghana' & Cote d'Voire & Botswana & Senegal & Nigeria \\
\hline-5.258 & --4.209 & 3.421 & -2.679 & -2.583 & -2.503 \\
\hline Kenya & Rwanda & Ethiopia & Tanzania & Swaziland & Uganda \\
\hline-1.626 & -.1 .306 & -1.257 & -.999 & -.9593 & -.8672 \\
\hline Benin & Gambia & Sierra Leone & Liberia & Equatorial G & Guina Bissau \\
\hline-.8081 & -.206 & -.782 & -.741 & -.654 & -.641 \\
\hline Niger & Chad & $\begin{array}{l}\text { Republic } \\
\text { Congo }\end{array}$ & Angola & Zambia & Zimbabwe \\
\hline-.633 & -.591 & -.563 & -.477 & -.462 & -.418 \\
\hline Central Rep Af & Sudan & Lesotho & Burundi & Madagascar & Mozambique \\
\hline
\end{tabular}

\subsection{Division of Cooperation Zones}

According to the results of the comprehensive distance indices between SSA countries, the comprehensive distance indices are divided into 4 intervals: They are minus $\infty, 5$, minus 3 , minus 1 , and $\infty$. As such there are four cooperation circles as shown in Figure 1 according to the comprehensive distance indices measurement result.

The first circle has the smallest comprehensive distance indices from SSA (circle 1)

\begin{tabular}{|l|l|l|l|l|l|}
\hline South Africa & Ghana & Cote d'Voire & Botswana & Senegal & Nigeria \\
\hline-5.258 & --4.209 & 3.421 & -2.679 & -2.583 & -2.503 \\
\hline
\end{tabular}




\section{Macrothink}

Journal of Management Research

ISSN 1941-899X

2020, Vol. 12, No. 4

The second circle has medium comprehensive distance indices, it encompasses, Circle 2.

\begin{tabular}{|l|l|l|l|l|l|}
\hline Kenya & Rwanda & Ethiopia & Tanzania & Swaziland & Uganda \\
\hline-1.626 & -.1 .306 & -1.257 & -.999 & -.9593 & -.8672 \\
\hline
\end{tabular}

The third circle has medium higher comprehensive distance indices, Circle 3.

\begin{tabular}{|l|l|l|l|l|l|}
\hline Benin & Gambia & Sierra Leone & Liberia & Equatorial G & Guina Bissau \\
\hline-.8081 & -.206 & -.782 & -.741 & -.654 & -.641 \\
\hline
\end{tabular}

The fourth circle is the highest comprehensive indices, Circle 4.

\begin{tabular}{|l|l|l|l|l|l|}
\hline Niger & Chad & $\begin{array}{l}\text { Republic } \\
\text { Congo }\end{array}$ & Angola & Zambia & Zimbabwe \\
\hline-.633 & -.591 & -.563 & -.477 & -.462 & -.418 \\
\hline
\end{tabular}

The first circle encompasses shortest or relatively shorter geographic distances and cultural distance from SSA, bordering on or close to SSA regions. These countries have the least barriers to cooperation, the lowest transaction costs, and the greatest possibility for cooperation. The 2 nd circle has relatively small comprehensive distances SSA, mainly including central Africa and South African countries. These countries have a relatively short geographic distance, factor endowment distance, and cultural distance from SSA barriers to cooperation. 


\section{MInstitute Macrothink $^{\text {Int }}$}

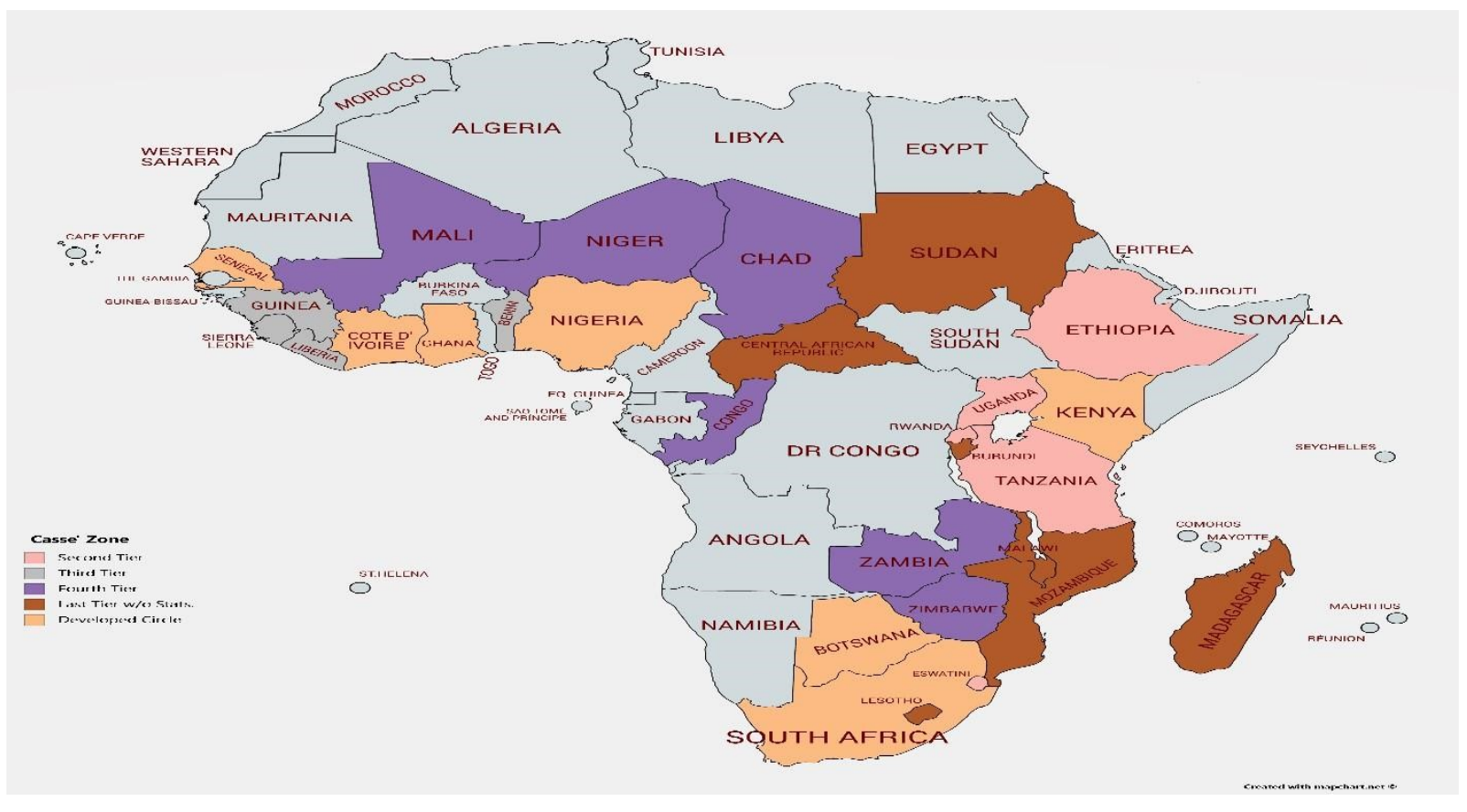

At each stage of the construction process, the density of the line in figure 2 represents the development degree of the cooperative network construction. The larger the density the closer the amount of time required to reach cooperation. This represents this different cooperation network construction stages. Different work needs to be done according to the characteristics of each stage. Therefore, divided the network construction process into four stages according to the delineation of circles: the initial stage, the development stage, The formation stage, and the improvement stage see figure two period at each stage of the construction process, the density of the line in Figure 2 represents the development degree of the cooperation network construction. The larger the line the closer the cooperation. According to the thinking of progress from point, line, playing to the whole area, and gradually formed the regional cooperation, the cooperation networks (Felbermayr, Jung, Toubai, 2010) between SA can be promoted as follows: 


\section{Macrothink}

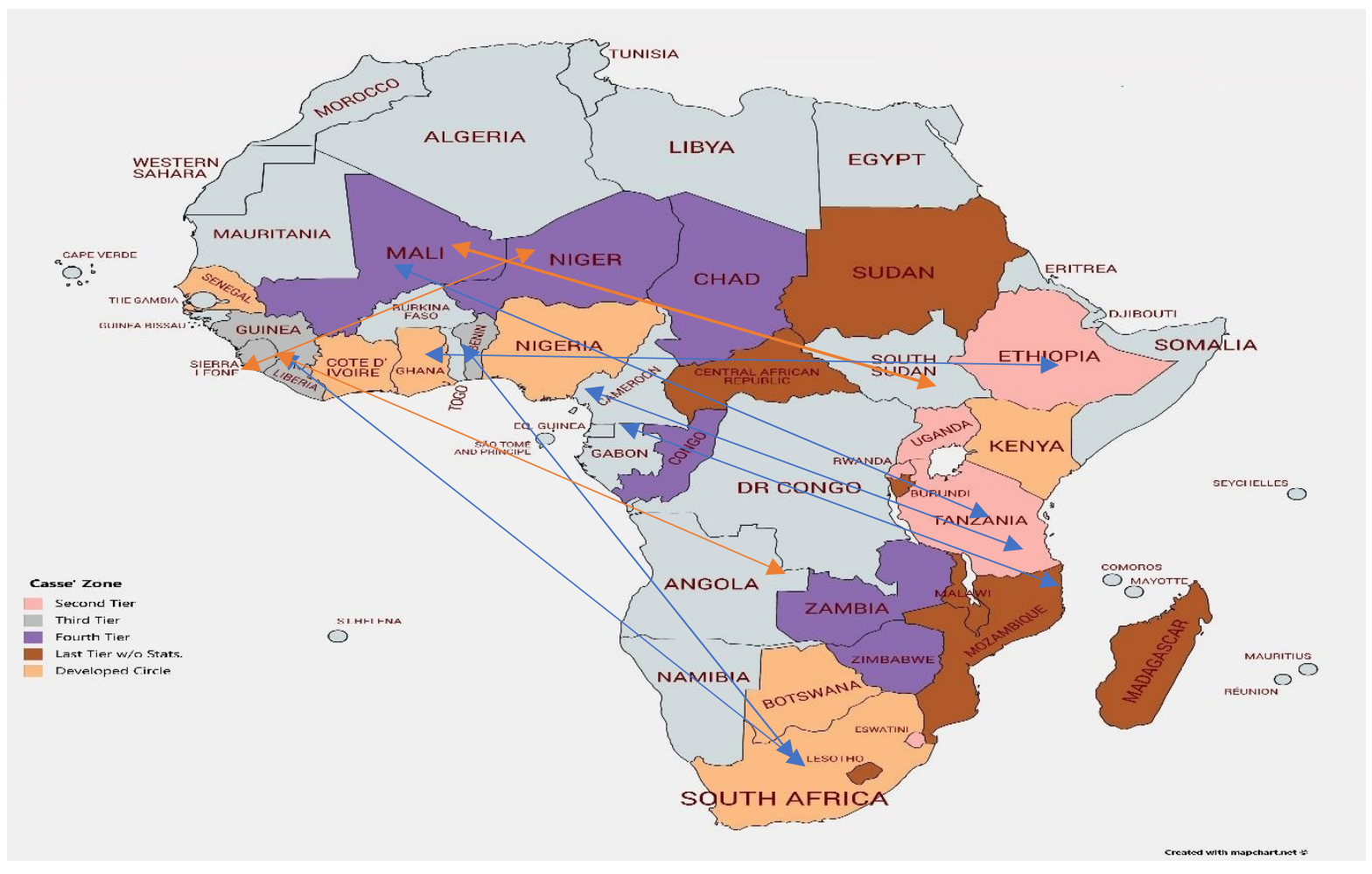

All zones connect with all others. Those taking the lead are the more developed countries, with circle. See country circle lists above.

The example is that the best developed go for the second tier, then for third, and so on. This is different than solely rolling out linearly. First there's an initial stage. At the initial stage of the cooperation network construction, countries along the route have limited understanding of initiatives and only a few countries have a good foundation for cooperation to be involved in further in-depth cooperation. SSA should have a leader in al development and exchange which has the smallest comprehensive distance indices and seek common interest to reach consensus on cooperation. To play a positive role in demonstrating and leading the cooperation, SSA should act as the praxis power, and accelerate the construction MOUs.

In the development stage of cooperation network construction, the cooperation activities between governments, institutions, and people will experience a marked increase, so the lines of cooperation network are becoming increasingly dense. The cooperation between SSA will take shape and appeal to some countries with relatively shorter geographic, factor endowment, cultural distance, factors from SSA at this stage SSA should further improve its cooperation mechanism that integrates economic, social, and ecological benefits so as to match cooperation planning with national and al policies of 2 nd circle countries (Festinger, 1950). Following the process, the 2 nd circle countries.

In the formation stage, and over time, more countries along the route will conduct further indepth cooperation, reaching the formation stage of the cooperation network construction. At this time, the cooperation network lines are denser. At this stage, the uncertainties about 
cooperation have been effectively reduced, and the cooperation mechanism has been improved. Therefore, the trading activities with the previous constrained countries will increase in the conditions of cooperation. During this SSA should enrich the contents and diversity of measures in regional cooperation and introduce flexible and open platforms for cooperation.

Finally, there is an improvement stage. After a longer development time, more communication activities have been completed, shortening the comprehensive distance indices between SSA African countries. This means that more countries have participated in cooperation within the SSA. At the improvement stage of the SSA cooperation organization the line density reaches a maximum in figure 2D. According to the cooperation network formation theory, the important feature of the network is that it emphasizes the interaction among many nations and seeks common interests instead of merely mutual interest. The network's competitiveness places emphasis on common interest, seeking coordinated development based on common interest, and establishing a high degree of mutual trust. Therefore at the improvement stage, the cooperation network construction would shift from the existing traditional cooperation concept circles to the combined use of resources among the countries to the formation and development of new resources, such as relations and networks for wider, deeper, and higher development of cooperation networks. At this stage SSA should innovate cooperation elements and expand the use of resources to attract 4th circle countries. this gets the improvement of cooperation networks so they form seamless cooperation and achieve improvement of cooperation networks so as to form seamless cooperation and development and achieve al governments concepts of sharing cooperation among the SSA countries.

After these four phases, a network of sustainable development from point to line, from line to area, and from area to region will be formed and confer the advantages for the SSA countries such as geographic proximity, economic complementarity, political trust, and cultural compatibility, that go into drivers of pragmatic cooperation for al growth. This network should realize construction of a multi-level and all-encompassing cooperation network between nations and the al cooperation areas.

\section{Conclusions and Policy Recommendations}

In this study, under the backdrop of al cooperation a cooperation network was designed and constructed from a multi distances perspective.

First, based on our above conclusions, the recommendation for this paper is that governments, organization, and institutions formulate a differentiated promotional plan according to development conditions and advantages of different countries to steadily promote their economic and also their development. Another consideration is whether they are able to successfully promote the participation of countries in different circles in the cooperation network construction, and whether or not the countries in the 1st and 2nd circles with smaller comprehensive distance indices, can create construction and production cooperation. For the countries in the 3rd and 4th circles with relatively bigger distance indices, the cooperation network could be started with cultural exchange and institutional development. The following specific recommendations are offered from the perspective of geographic factor endowment cultural and institutional distances: first the transportation and communication infrastructures 
in the cooperation countries can be improved to remove geographic distance barriers. This can come through online access between a social network creation it can come within the creation of video conferencing networks as well (Zukin, Dimaggio, 1990; Andrade, Rego 2017; Rezaei, Kirley, 2012). Additionally, frequent conferences among countries for cooperation can also be had so that budgets offerings and specializations can be decided. At present it is necessary to continue to strengthen infrastructure construction in terms of these factors thus forming an infrastructure network connecting countries along the route and improving inter regional transportation efficiency. The recommendation is to promote the construction of venues that strengthen the cooperation of logistics channels and establish a unified management organization, transportation rules, and reducing any clearance procedures. In terms of communication structure, to open up information channels, information network backbones should be constructed, such as a cross border optical fiber cable, an intercontinental connection with outside al institutions and governments, and even satellite communications equipment that are launched by the consortium or are part of a leased space or leased capacity.

Second, the distribution of supplier population should be rationalized to optimize the allocation of production and specialization. Institutions should comprehensively consider the major issues of distinctive competence such as regional orientation and specialization, development direction for specific markets or specific regions. institutional layout and resource integration, and then determine regional development plans through dialogue and consultation with countries along the routes. The regional development plans should aim at promoting the convergence of upstream and downstream at al chains as well as the associated industries in the cooperation network to scientifically achieve regional functionality. With respect to law of economic development, the economic zones, and commerce networks, as well as logistics centers should be constructed jointly to integrate demand and supply and specialization conditions within the network. As such the regional division system can be formed and deepened. Eventually, the production factors would flow better, and the regional production network of can be gradually improved.

Third, institutions countries governance and support organizations should actively promote cultural exchanges with the network organizations to reduce any cultural distance between them especially among the lines of different circles of cooperation and specialization areas that are unique to their particular region governments and organizations can hold various exchange activities such as cultural events and arts festival to display the ongoing cultural resources of institutions and countries along the institutional and cooperation routes for period these exchange activities would be beneficial for building cultural bridges and enhancing cultural identity. Second, they would be beneficial to deepen the understanding and friendship among the people in different countries, and civil exchanges should be concerned with activities such as mutual friendship institutions, non-governmental cooperation of organizations, and charity projects. Third, the development of international and intercontinental resources should be strengthened by creating exchange and clearance between countries and exchange channels. Overall, cultural exchange should be promoted to introduce a solid foundation for cooperation between countries. 


\section{Al Macrothink}

Journal of Management Research

ISSN 1941-899X

2020, Vol. 12, No. 4

Fourth, the establishment of institution systems should be strengthened to improve facilitation and transparency of al cooperation and governance. Presently, it is necessary to sign MOU's and memorandums of intergovernmental and many memorandums of interinstitutional cooperation with cooperation plans along routes based on consultation to mutual benefits, to build an intergovernmental coordination system of and exchange. Therefore, the al network construction should be more standardized, institutionalized, and legalized as it progresses. The recommendation is to establish free zones as soon as possible to reduce any barriers to improve facilitation Additionally countries and institutions can try to establish mutual recognition systems within the al cooperation zone to save import or export clearance time an on a more convenient trading environment.

Finally, this methodology can be adapted to more comprehensive uses for assessment. Jeffrey Sachs (2020) indicates that supplier or contractor vetting is hopelessly enamored with particular evaluations and not a stable evaluation system. For him, it would be much better if international organizations had a common way to vet and then be able to adapt to particular circumstance.

For Sachs, this expands into more general criteria for agency use involved with exploring competence of product lines, but ALSO assessing whether the impact for goods and services is likely to fit today and tomorrow. Second, decision frameworks regarding whether production or services processes are socially and environmentally responsible. Third, whether their value chains are also social and sustainably responsible in supply flow and disposition. Finally, Sachs argues that besides technical capacity, it is critical to assess good company or supplier citizenship in the effort to align business organizations to the specific processes at hand, put them into categories, and align them with the critical areas of application in the UN, and PCA.

Finally, this methodology

SSA n'est pas une zone casse'. On devrait investir plus dans l'économie.

This research was not funded by anyone save for the authors.

The authors declare there are no conflicts of interest in this research.

The authors declare they both participated substantially to the entire paper.

\section{References}

Aguilar, V.B., \& Montoya, M.S. (2013). Academic knowledge mobilization to promote cultural change in. Perspectives on Open and Distance Learning: Open al Resources: Innovation Research and Practice. Commonwealth of Learning, UNESCO Chair in OER. 17-32.

Anderson, J., \& Wincoop, E. (2000). Gravity with gravitas: A solution to the border puzzle. American Economic Review, 93,170-192. https://doi.org/10.1257/000282803321455214

Anderson, N., Potocnik, K., Zhao, Z. (2014). Innovation and creativity in organizations: A state of the science review, prospective commentary, and guiding framework. Innovation and Creativity. https://doi.org/10.1177/0149206314527128 
Andrade, R., \& Rego, L.C. (2017). The use of nodes as attributes in social network analysis with application to international trade networks. Journal of Statics and Mechanical Application. 491, 249-270. https://doi.org/10.1016/j.physa.2017.08.126

Apergis, N., \& Payne, J. (2011). The renewable energy consumption-growth nexus in Central America. Applied Energy, Elsevier. https://doi.org/10.1016/j.apenergy.2010.07.013

Baier, S., Bergstrand, J. (2009). Bonus Vetus OLS: A simple method for approximating international trade-cost effects using the gravity equation. Journal of International Economics, 77(1), 77-88. https://doi.org/10.1016/j.jinteco.2008.10.004

Barnard, Z., \& Van der Merwe, D. (2016). Innovation management for organizational sustainability in higher. International Journal for Sustainability in higher. March

Bollag, B., (2004). Improving tertiary in Sub-Saharan Africa: Things that work. African Region Human Development Working Paper Series: The World Bank.

Choi, C. (2002). The Linder Hypothesis Revisited. Applied Economics Letters Taylor and Francis. https://doi.org/10.1080/13504850110111234

DeGroot, H., Linders, G., \& Subramanian, U. (2004). The institutional determinants of bilateral trade patterns. Social Sciences, 57, 103-122. https://doi.org/10.1111/j.0023-5962.2004.00245.x

Downs, G., \& Mohr, L. (1979). Toward a Theory of Innovation. Administration and Society, 10(4), 379-408. https://doi.org/10.1177/009539977901000401

Edwards, C.T, \& Samimi, R. (1997). Japanese interfirm networks: Exploring seminal sources of success. Journal of Management Studies, 4, 449-510.

Elsass, P.M. (1994) Acculturation in acquired organizations: A force field perspective. Human Relations, 47, 431-353. https://doi.org/10.1177/001872679404700404

Felbermayr, G., Jung, B., \& Toubal, F. (2010) Ethnic networks formation and international trade. Annual Economics Review, 253, 41-70. https://doi.org/10.2307/41219109

Festinger, L.S, \& Schacter, K.W (1950). Social pressures in informal groups: A study of Human Factors in Housing. Stanford University Press, Palo Alto California. 249-261.

Hahn, J., Hausman, J. (2002). A new specification test for the validity of instrumental variables. Econometrica, 70, 163-189. https://doi.org/10.1111/1468-0262.00272

Gulati, R, Lavie, D. (2011). How do networks matter: Performance of interorganizational networks. Research in Organizational Behavior, 31, 207-224. https://doi.org/10.1016/j.riob.2011.09.005

Han, M.C., \& Jiang, C.C. (2017). The impact of political risk, culture distance, and bilateral relationships on China's OFDI. Finance and Economics, 2, 84-91.

Hecksher, E.F. (1919). The effect of foreign trade on the distribution of national income. Ekonomisk Tidskruft. 21. 


\section{Ml Macrothink}

Journal of Management Research

ISSN 1941-899X

2020, Vol. 12, No. 4

Hodgskinson-Williams, C., Paskevicius, M., \& Cox, G. (2013). 365 days of openness: The emergence of OER at the University of Capetown. Perspectives on Open and Distance Learning: Open al Resources: Innovation Research and Practice. Commonwealth of Learning, UNESCO Chair in OER. 34-46.

Jayaraj, A., Rottman, J., Lacity, M. (2006). A review of the predictors, linkages, and bias in IT innovation adoption research. Journal of Information Technology, 21(1). https://doi.org/10.1057/palgrave.jit.2000056

Kearney, M. (2009). Higher research and innovation: Charting the course of the changing dynamics of the knowledge society. In Meek, V.L., Teichler, U., Kearney, M.L. (eds) Higher Research, and Innovation: A report on the UNESCO Forum on higher research and knowledge. International Center for Research in Higher 2001-2009. 7-24.

Kostova, T. (1997). Country institutional profiles: Concepts and measurement. Academy of Management Proceedings 1997. https://doi.org/10.5465/ambpp.1997.4981338

Li, W., \& Liu, H. (2016). The construction of the Belt and Road from the perspective of multidimensional space, economy, culture, and institution. International Economic Trade Research, 6, 99-112.

Lin, J.Y., \& Plastovik, B. (2008). Higher and Development: Annual World Bank Conference on Development Economics Regional.

Lutz, J., Smetschka, B., \& Grima, N. (2017). Cooperation as a means for creating local systems-potentials and challenges. Sustainability, 9, 925. https://doi.org/10.3390/su9060925

Maturo, P. (2007). Higher quality assurance in Sub-Saharan Africa: Status, challenges, opportunities, and promising practices. Washington, DC: The International Bank for Reconstruction and Development, The World Bank.

McGreal, R., Kinuthia, W., \& Marshall S. (2014). Open al Resources: Innovation, Research and Practice. Tim McNamera (ed) Vancouver: Commonwealth of Learning, Athabasca .

Ng'ethe, N., Asse-Lumumba, N., Subotski, G., \& Addy, Essi-Sutherland. (2003). Higher Innovations in Sub-Saharan Africa, With specific reference to universities.

Odd, J., \& Michae, B. (1995). Strategic networks in small firms: Strategy research. Management Studies, 22-28.

Plotnikov, V., Vertakova, Y (2015) Formation of networks as a form of business integration. Proceedings in Economics and Finance, 240, 511-518. https://doi.org/10.1016/S2212-5671(15)00620-6

Qi, J.H., \& Li., L. (2012). Location choice of Chinese OFDI based on the threshold effect of cultural distance. Journal of International Trade, 12, 40-46.

Rezaei, G., \& Kirley, M. (2012). Social Networks facilitate player cooperation in the prisoner's dilemma. Journal of Statics and Mechanical Application. 23, 6199-6211, https://doi.org/10.1016/j.physa.2012.06.071 


\section{Macrothink}

Journal of Management Research

ISSN 1941-899X 2020, Vol. 12, No. 4

Ruggieri, A., Braccini, A. Poponi, S., \& Mosconi, E. (2016). A meta model of interorganizational cooperation for economic transition. Sustainability, 8, 1153-1169. https://doi.org/10.3390/su8111153

Sacerdoti, G. (2014). Trade and investment law: Institutional differences and substantive similarities. Review of Legal Studies, 9, 1-12. https://doi.org/10.1093/jrls/jlt011

Smith, A. (1904). An inquiry into the nature and causes of the wealth of nations. University of Chicago Press. Chicago, 13-28. https://doi.org/10.1086/251119

Soloaga, I., \& Winters, L.A. (2001). Regionalism in the nineties: Effects on trade. North American Journal of Economics and Finance. https://doi.org/10.1016/S1062-9408(01)00042-0

Song, J., \& Sun, Y.L. (2016) Research on the formation mechanism of cooperation innovation network competence. Management Review, 28, 67-75.

Straathof, B., Van Wincoop, E. (2003). Gravity with Gravitas: A solution to the border puzzle. American Economic Review, 93(1), 170-192. https://doi.org/10.1257/000282803321455214

Tinbergen, J. (1962). Shaping the world economy - Suggestions for international economic policy. The 20th Century Fund, New York. 22-28.

Wan, L., \& Gao, X. (2014). The influence if cultural, geographic, and institutional distance on import and export trade: An empirical test of trade data with 32 countries or regions, 5, 3948.

Xu, Z.Y. (2013). Application of social network analysis in economics. Economics Information, $10,61-72$.

Yin, Y.L., \& Liu, C (2017). Effect of cultural distance on bilateral trade flows along Belt and Road initiatives: Evidence from transnational trade. Economic Review, 8, 60-80.

Zhang, X.J, \& Peng N. (2017). Research on cooperation and trade promotion of the Belt and Road Initiative. Journal of the South China Normal University, 5, 22-27.

Zhou, Q., Shao, G. (2017) Research on determinants to form free trade areas in Asia Pacific Countries. Journal of International Trade. 9:71-82.

Zukin, S., Dimaggio, P. (1990). Structures of capital: Social organization of economy. Cambridge University Press. London. 22-56. 